Neurosurg Focus 19 (3):E9, 2005

\title{
Multiple root avulsions from the brachial plexus
}

\section{Case illustration}

\author{
Devin K. Binder, M.D., Ph.D., Daniel C. Lu, M.D., Ph.D., and Nicholas M. Barbaro, M.D.
}

Department of Neurological Surgery, University of California, San Francisco, California

\section{KEY WORDS - brachial plexus injury - nerve root avulsion • dorsal root entry zone lesioning}

Brachial plexus avulsion is one of the major injuries in motor vehicle accidents and may result in deafferentation pain. Neuropathic pain from avulsion injuries often responds to pharmacotherapy; however, in medically refractory cases surgery may be required. First introduced 30 years ago, dorsal root entry zone (DREZ) lesioning ${ }^{1}$ remains the main surgical option for these patients and is quite effective: in long-term studies up to $75 \%$ of patients had good pain control after DREZ lesioning. 2,3

This 46-year-old man presented with a 4-year history of decreased left hand strength and burning pain beginning at the elbow and radiating down the ulnar side of the forearm to the hand. His medical history included a motor vehicle accident in 2000. On neurological examination, his left hand and fingers displayed significant muscle atrophy. Flexion and extension of his wrist was preserved; however, he had paresis of lateral wrist movement. He could flex his index finger slightly, but had no independent movement of the other fingers. Sensation to fine touch and pinprick from the inner aspect of his elbow to the medial two fingers was decreased. Strength and sensation in the upper arm were normal.

A left lower brachial plexus injury (C7-T1) was diagnosed based on clinical findings and magnetic resonance (MR) studies (Fig. 1A and B). Despite treatment with gabapentin and amitriptyline, his intractable severe burning pain and paresthesias radiating from the elbow to the hand continued. He reported that the pain came in waves.

Because medical therapy had failed, DREZ lesioning was performed. A midline incision was made and an initial laminectomy of $\mathrm{C}-6, \mathrm{C}-7$, and T-1 was done. Opening of the cervical dura mater revealed empty foramina from avulsed (absent) roots on the left $\mathrm{C}-7, \mathrm{C}-$ 8 , and T-1, and intact contralateral roots (Fig. 1C and D). The laminectomy was extended to $\mathrm{C}-5$ to visualize the intact $\mathrm{C}-6$ nerve root; the intact T-2 nerve root was observed inferiorly. Neuromonitoring was used to evaluate the somatosensory and motor evoked responses to measure the dorsal column and corticospinal tract functions throughout this procedure. Thickened arachnoid mater was dissected away from the spinal cord. Using normal nerve roots above and below the site of injury, and the contralateral side as landmarks, the DREZ was identified. A Nashold dorsal root entry needle was inserted into the cleft between the lateral edge of the dorsal column (insertion angle $\sim 30^{\circ}$ ). Each lesion was made for 15 seconds at $75^{\circ} \mathrm{C}$ and a row of lesions was placed 1 to $2 \mathrm{~mm}$ apart between C-7 and T-1. There were no changes in somatosensory or motor evoked potentials during lesioning.

Postoperatively, the patient experienced immediate and complete resolution of neuropathic pain with no additional motor or sensory deficits, and remained free of pain at the 3-month follow-up evaluation. He continues to use oral pain medications, albeit at reduced dosages.

In long-term follow-up studies (14 months-10 years), up to $72 \%$ of patients treated with this procedure attained excellent and lasting pain relief. ${ }^{2}$ It is interesting to note that, unlike anterolateral cordotomy for intractable pain, DREZ lesioning is not associated with complications such as postcordotomy dysesthesias or pain, micturition problems, or respiratory compromise. ${ }^{4}$ In the cervical and lumbar spinal cord enlargements, complications of DREZ lesioning such as new weakness or sensory loss, and new paresthesias or dysesthesias are

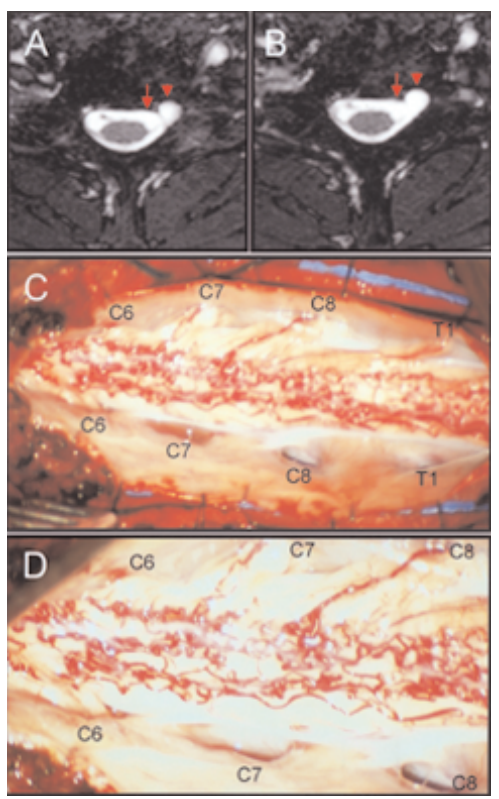

FIG. 1. A and B: Contiguous axial $\mathrm{T}_{2}$-weighted MR images demonstrating the absence of leftsided dorsal root, indicating root avulsion at $\mathrm{C}-7$ (arrows) associated with a pseudomeningocele ( $a r$ rowheads). C and D: Intraoperative photographs obtained after exposure of the cervical spinal cord and roots showing empty foramina on the left at C-7, C-8, and T-1, with preserved contralateral roots exiting the foramina (left $=$ bottom of laminotomy, right $=$ top). Note that the T-1 root is smaller than the C-8 root.

rare. This is not the case for DREZ lesioning procedures in the thoracic spinal cord. This is why DREZ lesions are not recommended for thoracic neuropathic pain such as postherpetic neuralgia. ${ }^{1}$

Recent surgical practice has incorporated both nerve grafts and DREZ procedures to treat weakness and pain..$^{5}$ In our case, because of the delay in presentation and the predominant symptom of pain, we only performed the DREZ procedure. Our case also illustrates that DREZ lesioning can be performed to treat neuropathic pain and a good outcome can be achieved long after the initial root avulsion (4 years later in our patient).

\section{References}

1. Binder DK, Barbaro NM: Cordotomy, in Follett KA (ed): Neurosurgical Pain Management. Philadelphia: WB Saunders, 2004, pp 165-171

2. Chen HJ, Lu K, Yeh MC: Combined dorsal root entry zone lesions and neural reconstruction for early rehabilitation of brachial plexus avulsion injury. Acta Neurochir Suppl 87:95-97, 2003

3. Friedman AH, Nashold BS Jr, Bronec PR: Dorsal root entry zone lesions for the treatment of brachial plexus avulsion injuries: a follow-up study. Neurosurgery 22:369-373, 1988

4. Nashold BS Jr: Current status of the DREZ operation: 1984. Neurosurgery 15:942-944, 1984

5. Thomas DG, Jones SJ: Dorsal root entry zone lesions (Nashold's procedure) in brachial plexus avulsion. Neurosurgery 15: 966-968, 1984

Manuscript received July 1, 2005; accepted in final form August 18, 2005.

Address reprint requests to: Nicholas M. Barbaro, M.D., Department of Neurological Surgery, M779 Moffitt Hospital, Box 0112, University of California, San Francisco, California 94143-0112. email: BarbaroN@ neurosurg.ucsf.edu. 
J Neurosurg 97:000-000, 2002 
J Neurosurg 97:000-000, 2002

Address reprint requests to: 